\title{
The impact of local work and residential balance on vehicle miles traveled A new direct approach
}

\section{Working Paper}

Author(s):

Loder, Allister; Tanner, Reto; Axhausen, Kay W. (D)

Publication date:

2017-04

Permanent link:

https://doi.org/10.3929/ethz-b-000186350

Rights / license:

In Copyright - Non-Commercial Use Permitted

Originally published in:

Arbeitsberichte Verkehrs- und Raumplanung 1134 


\title{
The impact of local work and residential balance on vehicle miles traveled: A new direct approach
}

\author{
Allister Loder \\ Reto Tanner \\ Kay W. Axhausen
}

Working paper 


\title{
The impact of local work and residential balance on vehicle miles traveled: A new direct approach
}

\author{
Allister Loder \\ Reto Tanner \\ Kay W. Axhausen \\ IVT \\ ETH Zürich \\ Schaufelweg 88 \\ IVT \\ ETH Zürich \\ CH-8093 Zürich \\ phone: +41-44-633 6258 \\ CH-3098 Schliern \\ CH-8093 Zürich \\ phone: \\ phone: +41-44-633 3943 \\ fax: +41-44-633 1057 \\ fax: +41-44-633 1057 \\ allister.loder@ivt.baug.ethz.ch retanner@gmx.ch \\ axhausen@ivt.baug.ethz.ch
}

April 2017

\section{Abstract}

This paper introduces a new approach for explaining the effects of spatial competition for opportunities based on a cumulative opportunities measure of accessibility. We focus on the case of the labor market where some municipalities offer too few workplaces for their local population, forcing some of their residents to long drives. We apply this new accessibility measure to explain households' annual mileage in Switzerland using a Heckman model to account for carless households.

We find that car travel demand is much greater in municipalities with a relative undersupply in the local labor market compared to a balanced or oversupplied local labor market. The results show that driving increases with greater distance to the labor market center. The model estimates allow policy makers and planners to quantify as a first assessment the expected average mileage in each municipality for new settlements and to identify municipalities with low expected annual mileage.

\section{Keywords}

Accessibility, land-use, built environment, vehicle miles traveled

\section{Preferred citation style}

Loder, A., R. Tanner and K. W. Axhausen (2017) The impact of local work and residential balance on vehicle miles traveled: A new direct approach, Working paper, 1134, Institute for Transport Planning and Systems (IVT), ETH Zurich, Zurich. 


\section{Introduction}

The relationship between travel and the built environment has been one of the most studied in urban planning. Neighborhoods with large development density, land use diversity, street connectivity, destination accessibility and lower distance to public transport are generally found to reduce driving (Ewing and Cervero, 2017). Typically, the motivation for driving is to reach destinations for activities such as work or leisure. Destination accessibility is a measure to quantify for a location the generalized costs to reach potential destinations, because it provides a measure of the spatial interaction of land-use and transportation systems (Hansen, 1959; Weis and Axhausen, 2009). While there is no one best measure of accessibility (Handy and Niemeier, 1997), Geurs and van Wee (2004) emphasized the need for accessibility measures that are relatively easy to interpret for researchers and policy makers in evaluating land-use and transportation changes. They concluded that these relatively easy to interpret measures typically lack many details, but complexity and difficulty of interpretation increases with higher levels of detail.

With an expected population growth in Switzerland at a rate of $0.7 \%$ from 8.4 million in 2015 to over 10 million in $2045^{1}$, additional drivers will increase the negative externalities of traffic related to ecological impact, time losses and infrastructure. For an optimal land-use strategy that minimizes these negative impacts, urban and transport planners need to understand how the built environment itself affects driving. There is general consensus on how measures of accessibility are related to driving: areas with greater levels of accessibility exhibit less driving (Ewing and Cervero, 2010, 2017). However, "perhaps the simplest approach" (Owen and Levinson, 2015) of defining accessibility, the cumulative opportunities measure, fails to take spatial competition effects for opportunities into account (Geurs and van Wee, 2004). This is particularly important for the labor market; too few available workplaces may force workers to drive longer distances, even though their place of residence provides generally high levels of job accessibility. Thus, to derive optimal land-use strategies, it is important to understand the effect of competition for workplaces while maintaining the readability of results. In terms of accessibility, so far, this remains an open task. In this paper, we address this gap. We propose a new measure of accessibility that builds upon the cumulative opportunities measure, but accounts for local job competition.

We generate the new accessibility measure with car travel times from the macroscopic Swiss national transport model. Travel times are available at traffic analysis zones (TAZ) level. This

\footnotetext{
1https://www.bfs.admin.ch/bfs/de/home/statistiken/arbeit-erwerb/ erwerbstaetigkeit-arbeitszeit/erwerbspersonen/szenarien-erwerbsbevoelkerung. assetdetail. $39909 . \mathrm{html}$
} 
zones follow in most instances the municipal borders, but are further subdivided in areas with high population density, i.e. in cities. With population and employment data available at TAZ level, we compute for each TAZ the cumulative opportunities measure of accessibility to population and to workplaces up to certain travel time threshold. We also control for accessible workplaces beyond this threshold up to a second, more distant, threshold. We then transform the three accessibility measures into ordinal variables and obtain the new accessibility measure by interacting the three ordinal accessibility measures. We use the new accessibility measure to analyze the effects of the population and workplace distribution on driving, measured by the annual mileage of a household. We account for carless households using Heckman's 1976 selection model. We not only find that compact developments exhibit less driving, but also that less competition for workplaces or less need to drive longer to workplaces reduces driving. To the best of our knowledge, this is the first analysis that combines the cumulative opportunities measure of accessibility with competition for opportunities, which has been addressed, so far, only in more complex accessibility measures (Geurs and van Wee, 2004) and the literature on excess commuting (Hamilton, 1982), which does not include an accessibility perspective.

The remainder of this paper is organized as follows. The next section provides a brief literature overview on measuring and analyzing the spatial distribution of population and workplaces relevant to travel behavior. Thereafter, we explain how we obtained the new accessibility measure and how we prepared the socio-demographic data for the analysis of households' driving behavior, which is followed by a discussion on methodological approaches for modeling car use. Then we present the results and subsequently discuss the new accessibility measure and our results.

\section{Background}

Accessibility is not only a transport, but also a social and economic indicator. Geurs and van Wee (2004) defined accessibility as "the extent to which land-use and transport systems enable (groups of) individuals to reach activities or destinations". An important distinction is between individual and locational accessibility. The first type of accessibility measures describe the ease of a traveler to reach destinations given individual constraints. The letter types of accessibility measure the costs of reaching potential destinations within a transportation system (Owen and Levinson, 2015).

Geurs and van Wee (2004) discussed perspectives on accessibility and identified four relevant components. First, a transportation component describing travel time, costs or speeds between origin and destination. Second, a land-use component describing amount, quality and spatial 
distribution of opportunities that are supplied at each destination, e.g. number of employed (Hansen, 1959), population (Killer et al., 2013) and or retail (Crozet et al., 2012). Third, a temporal component introducing temporal constraints for the availability of opportunities and individuals. Fourth, an individual component describing personal needs and constraints. Geurs and van Wee (2004) concluded that an accessibility measure should be sensitive to changes in all four components, however, "applying the full set of criteria would imply a level of complexity and detai lthat can probabily never be achieved in practice". Also, Horner (2004) noted as a limitation of individual accessibility measures that they are incapable of producing generalized assessments of intra-urban structure because they focus on personal geographies. Handy and Niemeier (1997) concluded that no best approach to measure accessibility exists, while Owen and Levinson (2015) called the location based measure of cumulative opportunities the "perhaps the simplest approach". In this approach, accessibility is the count of all opportunities at destination that are reachable within a specific time threshold (Morris et al., 1979). Another popular location-based accessibility measure was introduced by Hansen (1959). In his approach, opportunities at reachable destinations are weighted by a gravity-based function of, e.g. travel time, distance or costs, before summing up all reachable opportunities. In this gravity-based approach, opportunities at destinations farther away are less desirable, similar to decreasing gravitational force between more distant planets. However, both approaches face implementation limitations. While for cumulative opportunity measures one has to decide on the threshold values (Morris et al., 1979), for gravity-based approaches an appropriate weighting function has to be chosen and parametrized (Geurs and van Wee, 2004).

The interactions between the land-use and transportation system are approached as an optimization problem in the literature on excess or wasteful commuting (Ma and Banister, 2006; Barr et al., 2010); observed commuting patterns are compared to the average minimum commute, which is the solution of the optimization where, for a given distribution of residential and work locations, commuting trips are reallocated to minimize average travel costs. Figuratively speaking, workers are assigned to the closest working places in terms of travel time or distance, ignoring job qualifications (Hamilton, 1982, 1989). The measure of an average minimum commute is also considered to be a measure of the jobs-housing balance (Ma, 2006). Recently, Kanaroglou et al. (2015) summarized the literature on excess commuting and provided a review and evaluation of metrics used for assessing excess commute. We refer the interested reader to the detailed discussion of indicators and metrics in that paper. This approach covers the effect of competition for jobs and the requirement to drive longer if too few jobs are available, but it lacks the spatial aspects of accessibility and land-use measures.

In summary, the literature shows a variety of accessibility measures and different approaches such as excess commuting, to address the interaction between land-use, transportation systems and the competition for opportunities. However, depending on scope and objective of analysis, 
a distinct metric has to be chosen, while the researcher bears in mind the implications of the chosen metric. We choose - to illustrate our new approach - the relatively easy to interpret measure of cumulative opportunities measure of accessibility. 


\section{Data}

In this section, we first describe the procedure of obtaining the new accessibility measure and, second, the preparation of the socio-demographic data for explaining households' driving behavior by the new accessibility measure.

\subsection{Accessibility data}

Following the accessibility perspectives by Geurs and van Wee (2004), the proposed new accessibility measure is a location-based accessibility measures, precisely speaking a contour measures or cumulative opportunity measure. Despite limitations, this kind of measure has proven its applicability in many studies. Owen and Levinson (2015) called this approach "perhaps the simplest approach", because it simply counts of opportunities at destination that are reachable within time thresholds. In this analysis, we measure the competition of a local population for local workplaces in two regions. The first region, $R 1$, is limited by travel time threshold $c u t_{1}$ around a location. The second region, $R 2$, is defined between the travel time thresholds $c u t_{1}$ and $c u t_{2}$, assuming $c u t_{2}>c u t_{1}$.

In our model, the population in $R 1$ is competing for available jobs in $R 1$, but we also control for the level of available jobs in $R 2$ to reduce the bias introduced by arbitrary choosing the travel time thresholds (Morris et al., 1979). Thus, for each TAZ, we compute the accessibility to workplaces $\operatorname{Work}_{R 1}$ and the amount of population $\operatorname{Pop}_{R 1}$ for region $R 1$ with Equation 1 and 2 , respectively. $I(x)$ is an indicator function and equals to one if its argument is positive, including zero, and equals zero otherwise.

$$
\begin{aligned}
& \text { Work }_{R 1}=\log \left(\sum_{i=1}^{N}=\text { Work }_{i} \cdot f_{1}\left(t t_{i j}\right)\right), \quad f_{1}\left(t t_{i j}\right)=I\left(c u t_{1}-t t_{i j} \geq 0\right) \\
& \operatorname{Pop}_{R 1}=\log \left(\sum_{i=1}^{N}=\operatorname{Pop}_{i} \cdot f_{1}\left(t t_{i j}\right)\right), \quad f_{1}\left(t t_{i j}\right)=I\left(c u t_{1}-t t_{i j} \geq 0\right)
\end{aligned}
$$

We compute the accessibility to workplaces in $R 2$, or $_{R 2}$ by Equation 3 .

$\operatorname{Work}_{R 2}=\log \left(\sum_{i=1}^{N}=\right.$ Work $\left._{i} \cdot f_{2}\left(t t_{i j}\right)\right), \quad f_{2}\left(t t_{i j}\right)=I\left(c u t_{2}-t t_{i j} \geq c u t_{1}\right)$

We obtain the travel times $t t_{i j}$ from the centroid of each TAZ to all other TAZs from the Swiss 
Table 1: Overview of variants of the cut points for computing the accessibility groups

\begin{tabular}{rrr}
\hline Scenario & Cut $_{1}[\mathrm{~min}]$ & Cut $_{2}[\mathrm{~min}]$ \\
\hline 1 & 15 & 25 \\
2 & 10 & 20 \\
3 & 5 & 15 \\
\hline
\end{tabular}

national macroscopic traffic model for the year 2010. In total, the model has 2'949 TAZ within Switzerland. Their spatial distribution is shown in Figure 2 . It should be noted that the travel times do not include access times at origins or egress times at destinations.

We define the threshold values according to Table 1 for three different scenarios for a sensitivity analysis to discuss the issue of arbitrarily selecting the travel time thresholds. We address this further in the results and discussion section. Figure 1 shows the histograms of the three measures for each of the three scenarios. As expected, greater threshold values increase the number of accessible jobs, but also the population within $R 1$. Note that the graphs show the log of the measures.

We introduce competition of the population for jobs to these well-established accessibility measures by using the interaction of the three measures computed in Equations 12 and 3 ; Because an interaction of three continuous variables precludes a relatively easy interpretation of the results, we decided to make each of the three measures ordinal on a three level scale of High, Medium, Low. The levels are determined by each measure's population weighted terciles. Figure 2 shows the spatial distribution of population in $R 1$ for each TAZ on the three level scale. As expected, the zones with high population in $R 1$ are located in the urban areas, while those with medium levels are either smaller cities or in the agglomerations of large cities.

The final accessibility variable is then the interaction of all three ordinal accessibility measures. The resulting variable is not ordinal anymore, but nominal with 27 levels if all combinations exist. We use the following three character code for the final accessibility variable to distinguish the different levels: The first character indicates the population level in $R 1$, the second character the employment accessible in $R 1$, and the last character the employment accessible in $R 2$. For example, a TAZ coded with $M-H-L$ has medium levels of population in $R 1$, high levels of accessible jobs in $R 1$ and low levels of accessible jobs in $R 2$. 
Figure 1: Histograms of the thee used cumulative accessibility measures for the three scenarios. Each row correspond to one scenario.
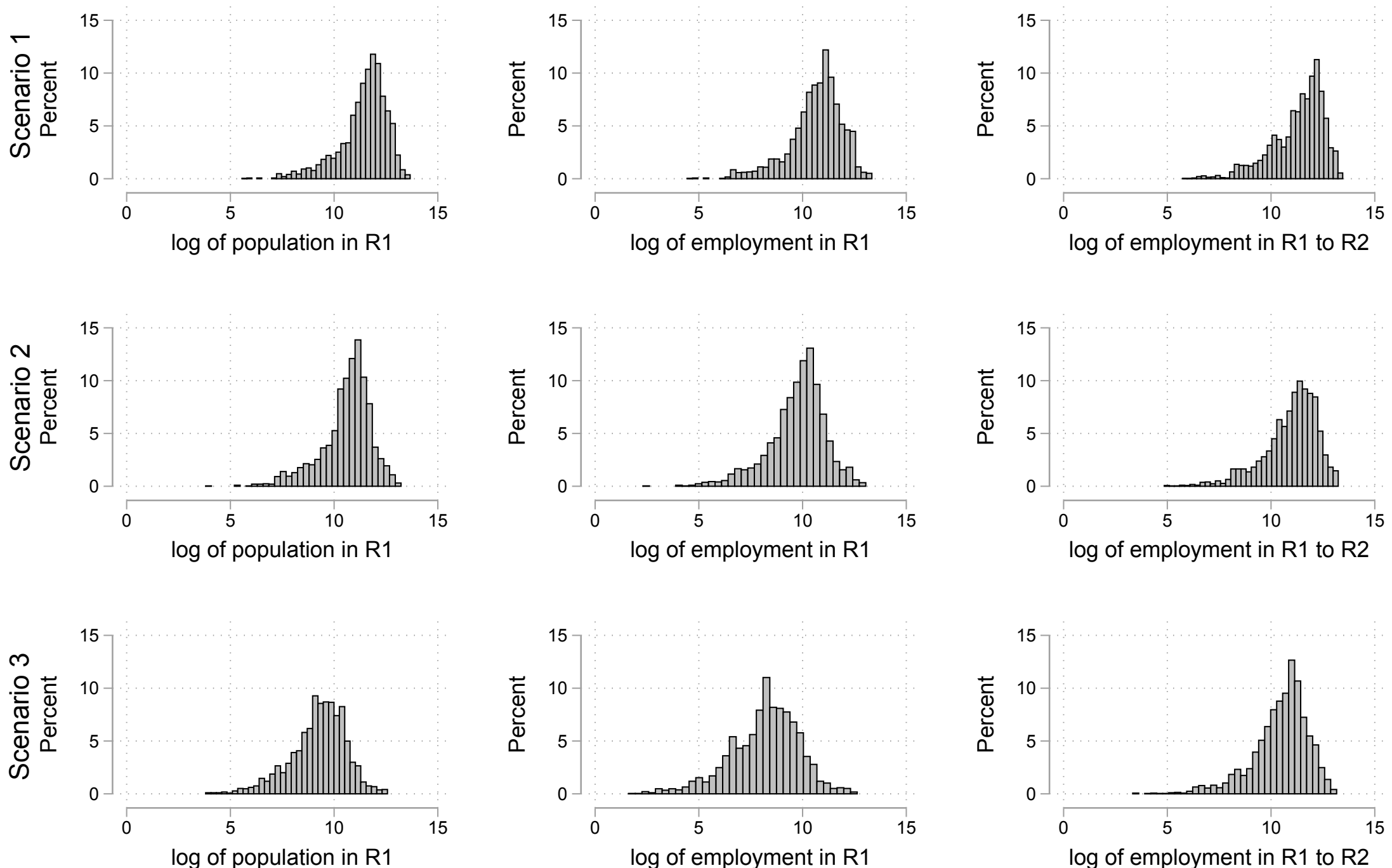
Figure 2: Spatial distribution of the population categories of the third scenario. 1 means low, 2 means medium and 3 means high.

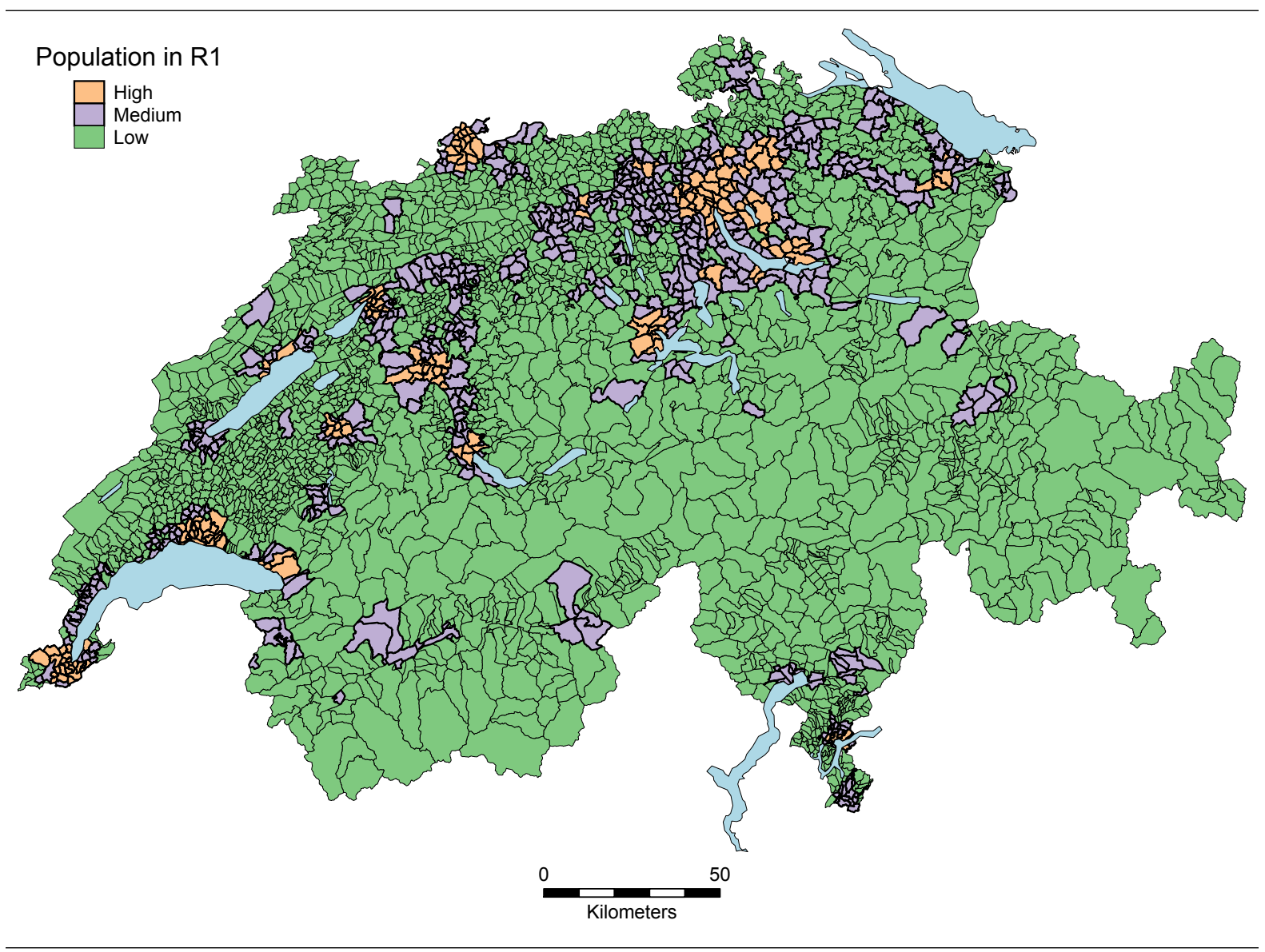




\subsection{Socio-economic data}

In this analysis, we measure driving as the household's annual mileage. Although our focus is on the effect of the spatial distribution of jobs and population and the annual mileage results from all kinds of trip purposes, we believe that this measure is the best available measure for driving for three reasons. First, one third of all trips are work related. Second, many workplaces, e.g. retail, also serve as a destination for other travelers. Thus, the distribution of workplaces to some extent also describes the distribution of other opportunities. Third, the data set does not report on the preferred commuting mode, but only report the chosen mode on the reported day. We control in our model for common explanatory variables.

Socio-economic data and information on annual vehicle use is provided by the Swiss transportation microcensus for the year 2010. The transportation microcensus is a large-scale survey carried out every five years with approximately $1 \%$ of the Swiss population. In 2010, 59'771 households were interviewed. From most households, one to two persons were randomly selected to report about their travel behavior (Swiss Federal Office of Statistics (BFS) and Swiss Federal Office of Spatial Development (ARE), 2012). We extract the following information from the household data set: gross monthly household income on a nine level scale, household type, a classification of the spatial typology of the household location (Swiss Federal Office of Spatial Development (ARE) et al. 2011) and a five level scale of the quality of public transport at the exact household location (Swiss Federal Office of Spatial Development (ARE), 2011). From the household person data set we extract the number of driving licenses, the number of household members and the number of household members of working age, i.e. between 16 und 65 .

We impute the income of those $24 \%$ households not reporting their income using Stata's multiple imputation routine with an ordered logit link. For explanatory variables, we select information of the household location (spatial typology, language region in Switzerland, access to public transport), of the household itself (household size, number of cars, household type) and of one surveyed household member (age, gender, labor market status). In total, the income of 4'430 households could not be imputed because no household members were interviewed in detail on their travel behavior.

We aggregate the annual mileage of each household, including the mileage information for both cars and motorbikes. As we have information on the interview date and the first registration date of each vehicle, we can correct the reported mileage for those vehicles that entered the household fleet less than twelve months prior the interview date to correspond to an annual mileage equivalent. We calculated the correction factor as the inverse of the difference between interview and registration date in days divided by 365 days. We set the minimal car usage period to 15 days to prevent overly large correction factors. If neither a registration year nor month was 
reported, we assume that the car entered the household fleet more than twelve months before the interview date.

The vehicle data set shows missing or incomplete reported mileage information. For this analysis, we select only households with complete reports of all their vehicles' mileage. In addition, we apply two filters to identify and remove outliers. The first defines a lower limit, $2000 \mathrm{~km}$ for cars and $500 \mathrm{~km}$ for motorcycles. We relax the lower bound filter for those households that have at least two cars above this limit to account for potential leisure cars. The second filter is an upper bound of a household's total annual mileage. We define this limit by using the concept of functional car ownership. The number of functional cars in a household is defined by the number of vehicles that can be moved simultaneously by all household members with a driving license. Thus, it is the minimum of number of cars $N_{\text {cars }}$ and driving licenses $N_{\text {licenses }}$ in the household. The upper bound of annual mileage is then given for each household by $k m_{\text {limit }}=25000+15000 \cdot \min \left(N_{\text {cars }}, N_{\text {licenses }}\right)$. The intercept of this function corresponds to twice the average mileage of household's first car and the slope to twice the average annual mileage of a household's second car (Swiss Federal Office of Statistics (BFS) and Swiss Federal Office of Spatial Development (ARE), 2012).

Because of missing or insufficient reported data as discussed above, the final sample is reduced to 40 '932 complete observations. Figure 3 shows the distribution of the dependent variable, the $\log$ of annual mileage per household. The data set has a share of $20 \%$ carless households 2 . These observations are not included in Figure 3 : Table 2 lists the summary statistics of all variables in the sample, except for the new accessibility variables which are given in Table 3 instead. In Table 2 we observe that households are approximately equally distributed across the different levels of quality of public transport at the household location. The spatial typology shows that one third of observations lives in urban areas, while another third lives in suburban areas. The last third of the population distributes across the different types of rural areas. We observe that the population does not distribute equally across income groups, but rather bell-shaped with a peak at CHF 4'001 to CHF 6000'3 In the sample, one third of all households are single households, another third are couple households, while the remaining split between families (20\%) and other household types. In the table for continuous predictors, we compute the statistics by omitting the observations not covered by the variable, e.g. the number of people at working age in a family households is only evaluated for family households.

In Table 3, we find that, when summing up all households by $P o p_{R 1}$ levels, i.e. $H, M$ and $L$ groups of the first character in the code, shows that our sample also distributes equally across groups as intended by the population weighted terciles. We observe for the first and second

\footnotetext{
${ }^{2}$ This value is obtained using the probability weights of the census.

${ }^{3}$ In 2017, the exchange rate between the Swiss Franc and the US Dollar was around unity.
} 
Figure 3: Histogram of the log of households' annual mileage. Carless households are omitted.

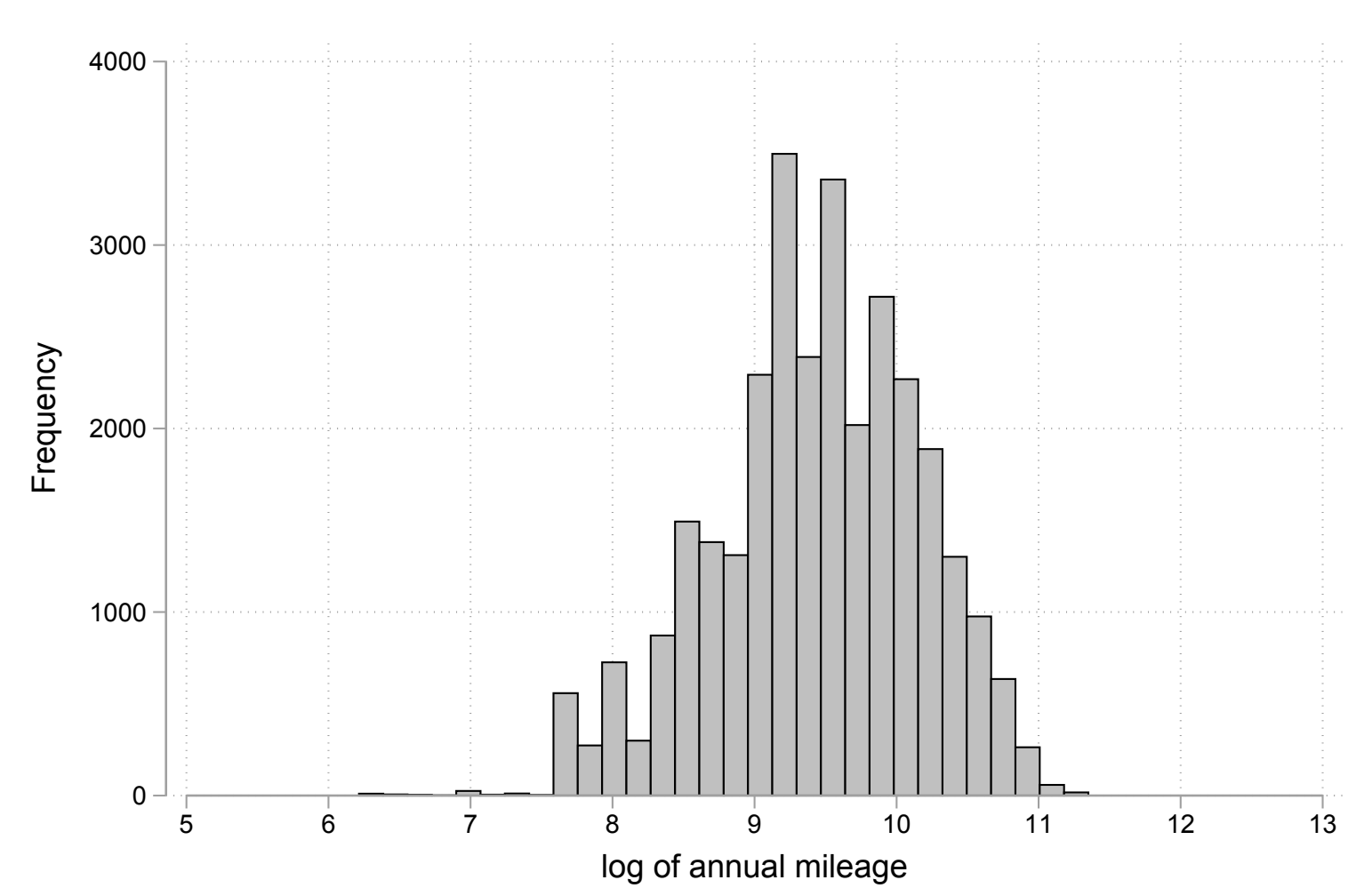

scenario that some accessibility levels have only few observations and that the third scenario covers two more accessibility levels than the first two scenarios. Note that not all combinations of $H, M$ and $L$ exist, i.e. we have no zones in the sample that has low levels of population but high levels of employment and no zones with high levels of population but low levels of employment. 
Table 2: Summary statistics of the entire sample, except for the new accessibility variable.

(a) Categorical explanatory variables.

\begin{tabular}{ll}
\hline & Share \\
\hline Quality of public transport at household location & \\
Level A: very good & 0.139 \\
Level B: good & 0.170 \\
Level C: moderate & 0.210 \\
Level D: low & 0.259 \\
Level E: very low & 0.221 \\
Spatial typology at household location & \\
Centers & 0.347 \\
Suburban & 0.309 \\
High-income & 0.045 \\
Periurban & 0.118 \\
Touristic & 0.026 \\
Industry and tertiary sector & 0.064 \\
Rural-commuting & 0.043 \\
Mixed-agrarian & 0.042 \\
Agrarian & 0.007 \\
Gross monthly household income & \\
Less than CHF 2'000 & 0.043 \\
CHF 2'000 to 4'000 & 0.226 \\
CHF 4'001 to 6'000 & 0.253 \\
CHF 6'001 to 8'000 & 0.187 \\
CHF 8'001 to 10'000 & 0.121 \\
CHF 10'001 to 12'000 & 0.073 \\
CHF 12'001 to 14'000 & 0.036 \\
CHF 14'001 to 16'000 & 0.025 \\
More than CHF 16'000 & 0.037 \\
Household type & \\
Cingle & 0.354 \\
Family & 0.370 \\
Other & 0.210 \\
\hline Observations & 0.065 \\
\hline
\end{tabular}

(b) Continuous explanatory variables.

\begin{tabular}{lrrrrr}
\hline & N & Mean & SD & Min & Max \\
\hline Log of annual mileage & 30658 & 9.438 & 0.734 & 6.215 & 11.350 \\
Number of persons of working age in couple households & 15133 & 1.205 & 0.926 & 0.000 & 6.000 \\
Number of persons of working age in family households & 8616 & 2.704 & 0.927 & 0.000 & 7.000 \\
Number of persons of working age in other households & 2674 & 1.914 & 0.967 & 0.000 & 11.000 \\
\hline
\end{tabular}


Table 3: Number of households in each accessibility level by scenario of travel time thresholds.

\begin{tabular}{lrrr}
\hline Accessibility level & Scenario 1 & Scenario 2 & Scenario 3 \\
\hline H-H-H & 5174 & 5214 & 5767 \\
H-H-M & 2096 & 4860 & 5055 \\
H-H-L & 5265 & 2916 & 1656 \\
H-M-H & 539 & 547 & 784 \\
H-M-M & 356 & 103 & 560 \\
H-M-L & 0 & 0 & 371 \\
H-L-H & 0 & 0 & 0 \\
H-L-M & 0 & 0 & 0 \\
H-L-L & 0 & 0 & 0 \\
M-H-H & 74 & 360 & 667 \\
M-H-M & 658 & 271 & 547 \\
M-H-L & 187 & 0 & 393 \\
M-M-H & 6439 & 5280 & 3855 \\
M-M-M & 6130 & 5097 & 4415 \\
M-M-L & 594 & 2546 & 4506 \\
M-L-H & 313 & 784 & 623 \\
M-L-M & 543 & 507 & 410 \\
M-L-L & 0 & 223 & 128 \\
L-H-H & 228 & 402 & 281 \\
L-H-M & 394 & 1459 & 1042 \\
L-H-L & 1001 & 1113 & 1457 \\
L-M-H & 4113 & 2901 & 2959 \\
L-M-M & 6803 & 6321 & 5357 \\
L-M-L & 0 & 0 & 0 \\
L-L-H & 0 & 0 & 0 \\
L-L-M & 25 & 28 & 0 \\
L-L-L & 09 \\
\hline & 0 & & \\
\hline
\end{tabular}




\section{Methodology}

For modeling driving, no single methodology exists. One can present a list of methodological and behavioral issues that must - in principle - be considered. For example, endogeneity of car ownership in car use (Bhat and Sen, 2006, Bhat et al., 2014), residential self-selection of households with a preference for cars into car friendly locations (Mokhtarian and Cao, 2008; Cao et al., 2009; Ewing and Cervero, 2010) or spatial autocorrelation of observations (Clark, 2007 ; Bhat et al., 2016), but given the scope of analysis, many of these issues have to be accepted. For example, Cervero and Kockelman (1997) noted that "the relationship between control variables like vehicle ownership and built environment could be endogenous, e.g. compact settings reduce vehicle ownership. However, the availability of cross-sectional data precluded any efforts to simultaneously estimate equations to control for possible estimation biases".

We could have used the methodological approaches combining ownership and use by Bhat and Sen (2006) and Bento et al. (2005), but we refrain from applying them for at least two reasons. First, these methods require cost information, but such detailed data is not available to us. Second, our objective is to provide a relatively easy to interpret accessibility measure and we do not want to distract the reader by introducing advanced econometric models and make the interpretation of results more complex. Thus, as our sample has around $20 \%$ carless households with no observed annual mileage, we use Heckman's (1976, 1979) approach of sample selection to account for carless households. The error terms of the selection and outcome equation are allowed to correlate with $\rho$. If $\rho$ is significantly different from zero, not considering the sample selection would result in biased estimates of the outcome equation. In the sample selection, we model whether a household has at least one vehicle, similar to Karlaftis and Golias (2002). In the outcome equation, we regress the natural logarithm of annual mileage on the explanatory variables. We use the logarithm of mileage to avoid the issue of non-negativity, which is common in literature (Bhat et al., 2014, Cervero and Duncan, 2006; Bento et al., 2005).

The transportation microcensus reports probability weights of each observation. This means that households were not randomly selected from the population. For instance, some cantons asked for additional surveyed households throughout the canton or for specific agglomerations. Thus, the observations of these cantons and agglomerations are oversampled. This oversampling is then captured in the probability weights. Because households with cars, but no or insufficient reporting of annual vehicle kilometers, had to be omitted from the data set, we had to reweight observations proportionally to maintain the same share of carless households throughout the analysis. 


\section{Results}

Table 4 presents the model estimates for households' annual mileage with the Heckman correction for carless households. The estimates are grouped by the scenario of the threshold values for calculating the cumulative opportunities measure of accessibility, see Table 1. For model identification, we use quality of public transport at the household location as an instrument that only affects the likelihood of being carless, but not mileage. Arguably, in Switzerland, households with good access to public transport do not require a car and use public transport as a legitimate substitute. In all models, we find $\rho$ to be negative and significantly different from zero. This means that common unobserved factors affect selection and the outcome in opposite directions and that standard regression analysis on annual mileage would result in biased estimates (Heckman, 1976).

The model estimates show that the likelihood of having a car in the household increases with a decreasing quality of public transport at the household location. The control variables in the selection equation show the expected effects: the probability of not being carless increases with household income, couples and families have greater probability of car ownership than single households, and the number of persons of working age increase the probability further. Living in the city center shows the lowest probability of car ownership, while the effect is strongest for periurban and rural commuting municipalities. We find that the estimates are robust regarding the three different scenarios. We also include the new accessibility variable in the selection equation as an explanatory variable, but with our focus on driving, we do not report and discuss it further.

The new accessibility variable, which is in all models referenced to the base category of $\mathrm{H}-\mathrm{H}-\mathrm{H}$ shows for some levels significant effects on annual mileage, whereas the number of significant estimates increases from scenario 1 to 3 . We attribute this to a finer spatial resolution and expect that, first, too large threshold values blurr spatial effects and, second, some levels contain only few observations, e.g. 25 observations in level $L-M-H$ of the first scenario (see Table 3 ). Regarding the significant effects, we observe that locations with larger population levels show less driving. This result is not surprising and well supported by the existing literature (Ewing and Cervero, 2017). However, we have to acknowledge that some estimates, both significant and insignificant, are rather close to each other. Therefore, we tested the hypothesis whether estimates from identical levels of $W o r k_{R 1}$ and $P o p_{R 1}$ are significantly different from each other. In case we do not find a significant difference, we pooled those estimates and estimated the model again. The results of these efforts are given for all three scenarios in Table 5 . 
Table 4: Results of the Heckman model using unpooled accessibility variables.

\begin{tabular}{|c|c|c|c|c|c|c|c|c|c|c|c|c|}
\hline \multirow{3}{*}{ Accessibility } & \multicolumn{4}{|c|}{ Scenario 1} & \multicolumn{4}{|c|}{ Scenario 2} & \multicolumn{4}{|c|}{ Scenario 3} \\
\hline & \multicolumn{2}{|c|}{ Log of annual mileage } & \multicolumn{2}{|c|}{ Car household } & \multicolumn{2}{|c|}{ Log of annual mileage } & \multicolumn{2}{|c|}{ Car household } & \multicolumn{2}{|c|}{ Log of annual mileage } & \multicolumn{2}{|c|}{ Car household } \\
\hline & & & & & & & & & & & & \\
\hline H-H-H & (ref.) & & (ref.) & & (ref.) & & (ref.) & & (ref.) & & (ref.) & \\
\hline H-H-M & -0.004 & $(0.022)$ & 0.030 & $(0.040)$ & -0.031 & $(0.018)$ & 0.036 & $(0.031)$ & $-0.039^{*}$ & $(0.019)$ & $-0.074^{*}$ & $(0.030)$ \\
\hline H-H-L & $-0.080^{* * * *}$ & $(0.017)$ & $0.082^{* *}$ & $(0.031)$ & $-0.158^{* * *}$ & $(0.021)$ & $0.076^{*}$ & $(0.036)$ & $0.064^{*}$ & $(0.027)$ & $0.138^{* *}$ & $(0.046)$ \\
\hline H-M-H & 0.057 & $(0.035)$ & 0.095 & (0.079) & 0.040 & $(0.035)$ & 0.108 & $(0.075)$ & 0.027 & $(0.031)$ & $0.155^{*}$ & $(0.063)$ \\
\hline H-M-M & -0.075 & $(0.050)$ & -0.024 & $(0.078)$ & 0.016 & $(0.073)$ & 0.244 & $(0.151)$ & $0.130^{* * *}$ & $(0.038)$ & 0.089 & $(0.083)$ \\
\hline H-M-L & & & & & & & & & $0.203^{* * * *}$ & (0.047) & 0.104 & $(0.081)$ \\
\hline M-H-H & -0.076 & $(0.093)$ & 0.140 & $(0.203)$ & 0.034 & $(0.038)$ & 0.115 & (0.094) & $0.127^{* * * *}$ & $(0.033)$ & 0.061 & $(0.068)$ \\
\hline M-H-M & 0.006 & $(0.032)$ & -0.114 & (0.069) & 0.025 & $(0.051)$ & 0.207 & $(0.117)$ & 0.004 & $(0.038)$ & $0.139^{*}$ & $(0.071)$ \\
\hline M-H-L & -0.085 & $(0.069)$ & -0.147 & $(0.120)$ & & & & & $0.216^{* * *}$ & $(0.045)$ & $0.598^{* * * *}$ & $(0.099)$ \\
\hline M-M-H & $0.060^{* * * *}$ & $(0.016)$ & $0.140^{* * *}$ & $(0.032)$ & $0.065^{* * *}$ & $(0.017)$ & $0.194^{* * *}$ & $(0.035)$ & $0.135^{* * * *}$ & $(0.017)$ & $0.153^{* * * *}$ & $(0.037)$ \\
\hline M-M-M & $0.069^{* * * *}$ & $(0.016)$ & $0.219^{* * *}$ & $(0.033)$ & $0.064^{* * *}$ & $(0.017)$ & $0.160^{* * * *}$ & $(0.033)$ & $0.133^{* * *}$ & $(0.017)$ & $0.177^{* * * *}$ & $(0.036)$ \\
\hline M-M-L & $0.142^{* * * *}$ & $(0.036)$ & $0.335^{* * * *}$ & $(0.076)$ & $0.093^{* * *}$ & $(0.021)$ & $0.377^{* * * *}$ & $(0.039)$ & $0.164^{* * * *}$ & $(0.018)$ & $0.354^{* * * *}$ & $(0.035)$ \\
\hline M-L-H & $0.149^{* * * *}$ & $(0.042)$ & 0.178 & $(0.116)$ & $0.120^{* * * *}$ & $(0.029)$ & $0.243^{* * *}$ & $(0.066)$ & $0.155^{* * * *}$ & $(0.032)$ & $0.177^{*}$ & $(0.077)$ \\
\hline M-L-M & 0.070 & $(0.039)$ & $0.334^{* * *}$ & $(0.080)$ & $0.159^{* * *}$ & $(0.035)$ & 0.169 & $(0.097)$ & $0.200^{* * * *}$ & $(0.042)$ & $0.199^{*}$ & $(0.101)$ \\
\hline M-L-L & & & & & 0.075 & $(0.055)$ & $0.253^{*}$ & $(0.127)$ & $0.198^{*}$ & $(0.077)$ & 0.162 & $(0.155)$ \\
\hline L-M-H & 0.114 & $(0.113)$ & 0.747 & $(0.442)$ & $0.345^{* *}$ & $(0.113)$ & 0.156 & $(0.353)$ & $0.248^{* *}$ & $(0.078)$ & 0.299 & $(0.217)$ \\
\hline L-M-M & $0.131^{* *}$ & $(0.051)$ & $0.312^{*}$ & $(0.123)$ & $0.174^{* * *}$ & $(0.038)$ & $0.403^{* * *}$ & $(0.099)$ & $0.196^{* * *}$ & $(0.042)$ & $0.368^{* * *}$ & $(0.110)$ \\
\hline L-M-L & $0.087^{*}$ & $(0.041)$ & $0.563^{* * *}$ & $(0.083)$ & $0.131^{* * *}$ & $(0.025)$ & $0.338^{* * *}$ & $(0.051)$ & $0.171^{* * *}$ & $(0.031)$ & $0.352^{* * * *}$ & $(0.066)$ \\
\hline L-L-H & $0.079^{* *}$ & $(0.027)$ & $0.217^{* * *}$ & $(0.063)$ & $0.170^{* * *}$ & $(0.027)$ & $0.369^{* * * *}$ & $(0.067)$ & $0.204^{* * * *}$ & $(0.023)$ & $0.301^{* * * *}$ & $(0.060)$ \\
\hline L-L-M & $0.139^{* * * *}$ & $(0.019)$ & $0.325^{* * *}$ & $(0.039)$ & $0.132^{* * * *}$ & $(0.020)$ & $0.363^{* * *}$ & $(0.046)$ & $0.242^{* * *}$ & $(0.021)$ & $0.310^{* * * *}$ & $(0.049)$ \\
\hline L-L-L & $0.103^{* * *}$ & $(0.017)$ & $0.281^{* * *}$ & $(0.035)$ & $0.111^{* * *}$ & $(0.018)$ & $0.263^{* * * *}$ & $(0.037)$ & $0.216^{* * *}$ & $(0.020)$ & $0.228^{* * *}$ & $(0.043)$ \\
\hline \multicolumn{13}{|l|}{ Gross monthly household income } \\
\hline Less than CHF 2'000 & (ref.) & & (ref.) & & (ref.) & & (ref.) & & (ref.) & & (ref.) & \\
\hline CHF 2'000 to $4^{\prime} 000$ & 0.005 & $(0.033)$ & $0.382^{* * *}$ & $(0.040)$ & 0.004 & $(0.033)$ & $0.376^{* * * *}$ & $(0.040)$ & 0.009 & $(0.033)$ & $0.376^{* * * *}$ & $(0.040)$ \\
\hline CHF 4'001 to 6'000 & $0.154^{* * *}$ & $(0.034)$ & $0.954^{* * *}$ & $(0.040)$ & $0.157^{* * *}$ & $(0.033)$ & $0.946^{* * *}$ & $(0.040)$ & $0.166^{* * *}$ & $(0.033)$ & $0.943^{* * * *}$ & $(0.040)$ \\
\hline CHF 6'001 to $8^{\prime} 000$ & $0.260^{* * *}$ & $(0.034)$ & $1.232^{* * *}$ & $(0.043)$ & $0.264^{* * *}$ & $(0.034)$ & $1.222^{* * * *}$ & $(0.043)$ & $0.275^{* * *}$ & $(0.034)$ & $1.221^{* * *}$ & $(0.043)$ \\
\hline CHF 8'001 to $10^{\prime} 000$ & $0.376^{* * *}$ & $(0.035)$ & $1.333^{* * *}$ & $(0.047)$ & $0.380^{* * *}$ & $(0.034)$ & $1.325^{* * *}$ & $(0.047)$ & $0.390^{* * *}$ & $(0.034)$ & $1.319^{* * *}$ & $(0.047)$ \\
\hline CHF $10^{\prime} 001$ to $12^{\prime} 000$ & $0.419^{* * *}$ & $(0.036)$ & $1.500^{* * * *}$ & $(0.055)$ & $0.422^{* * *}$ & $(0.036)$ & $1.489^{* * * *}$ & $(0.055)$ & $0.433^{* * * *}$ & $(0.035)$ & $1.482^{* * * *}$ & $(0.055)$ \\
\hline CHF $12^{\prime} 001$ to $14^{\prime} 000$ & $0.424^{* * *}$ & $(0.039)$ & $1.544^{* * *}$ & $(0.071)$ & $0.430^{* * *}$ & $(0.038)$ & $1.537^{* * * *}$ & $(0.071)$ & $0.441^{* * * *}$ & $(0.038)$ & $1.529^{* * * *}$ & $(0.071)$ \\
\hline CHF $14^{\prime} 001$ to $16^{\prime} 000$ & $0.506^{* * *}$ & $(0.040)$ & $1.495^{* * *}$ & $(0.081)$ & $0.511^{* * *}$ & $(0.039)$ & $1.483^{* * * *}$ & $(0.081)$ & $0.526^{* * *}$ & $(0.039)$ & $1.482^{* * * *}$ & $(0.082)$ \\
\hline More than CHF 16'000 & $0.503^{* * *}$ & $(0.039)$ & $1.676^{* * *}$ & $(0.074)$ & $0.507^{* * *}$ & $(0.038)$ & $1.664^{* * *}$ & $(0.074)$ & $0.521^{* * * *}$ & $(0.038)$ & $1.653^{* * * *}$ & $(0.074)$ \\
\hline Spatial typology & & & & & & & & & & & & \\
\hline Centers & (ref.) & & (ref.) & & (ref.) & & (ref.) & & (ref.) & & (ref.) & \\
\hline Suburban & $0.143^{* * *}$ & $(0.012)$ & $0.370^{* * * *}$ & $(0.022)$ & $0.132^{* * *}$ & $(0.012)$ & $0.353^{* * * *}$ & $(0.022)$ & $0.095^{* * *}$ & $(0.012)$ & $0.298^{* * *}$ & $(0.023)$ \\
\hline High-income & $0.153^{* * *}$ & $(0.021)$ & $0.437^{* * *}$ & $(0.046)$ & $0.121^{* * *}$ & $(0.021)$ & $0.413^{* * * *}$ & $(0.045)$ & $0.085^{* * *}$ & $(0.022)$ & $0.353^{* * *}$ & $(0.046)$ \\
\hline Periurban & $0.261^{* * * *}$ & $(0.015)$ & $0.539^{* * *}$ & $(0.036)$ & $0.238^{* * * *}$ & $(0.014)$ & $0.508^{* * *}$ & $(0.036)$ & $0.185^{* * *}$ & $(0.016)$ & $0.453^{* * *}$ & $(0.037)$ \\
\hline Touristic & $0.114^{* * *}$ & $(0.029)$ & $0.152^{* *}$ & $(0.059)$ & $0.103^{* * *}$ & $(0.029)$ & $0.170^{* *}$ & $(0.060)$ & 0.044 & $(0.030)$ & $0.150^{*}$ & $(0.061)$ \\
\hline Industry and tertiary sector & $0.222^{* * *}$ & $(0.018)$ & $0.319^{* * *}$ & $(0.041)$ & $0.198^{* * *}$ & $(0.018)$ & $0.308^{* * * *}$ & $(0.042)$ & $0.133^{* * * *}$ & $(0.020)$ & $0.291^{* * * *}$ & $(0.047)$ \\
\hline Rural-commuting & $0.331^{* * *}$ & $(0.020)$ & $0.511^{* * *}$ & $(0.053)$ & $0.298^{* * *}$ & $(0.020)$ & $0.477^{* * *}$ & $(0.054)$ & $0.239^{* * *}$ & $(0.022)$ & $0.438^{* * *}$ & $(0.056)$ \\
\hline Mixed-agrarian & $0.258^{* * * *}$ & $(0.021)$ & $0.496^{* * *}$ & $(0.052)$ & $0.240^{* * *}$ & $(0.021)$ & $0.475^{* * *}$ & $(0.053)$ & $0.178^{* * *}$ & $(0.023)$ & $0.472^{* * *}$ & $(0.056)$ \\
\hline Agrarian & $0.340^{* * * *}$ & $(0.046)$ & $0.292^{* *}$ & $(0.105)$ & $0.321^{* * *}$ & $(0.046)$ & $0.287^{* *}$ & $(0.105)$ & $0.263^{* * *}$ & $(0.047)$ & $0.293^{* *}$ & $(0.107)$ \\
\hline Household type & & & & & & & & & & & & \\
\hline Single & (ref.) & & (ref.) & & (ref.) & & (ref.) & & (ref.) & & (ref.) & \\
\hline Couple & $-0.163^{* * *}$ & $(0.015)$ & $0.676^{* * *}$ & $(0.027)$ & $-0.159^{* * *}$ & $(0.014)$ & $0.674^{* * * *}$ & $(0.027)$ & $-0.157^{* * *}$ & $(0.014)$ & $0.671^{* * * *}$ & $(0.027)$ \\
\hline Couple: Persons in working age & $0.237^{* * *}$ & $(0.007)$ & $0.035^{*}$ & $(0.017)$ & $0.237^{* * *}$ & $(0.007)$ & $0.036^{*}$ & $(0.017)$ & $0.237^{* * *}$ & $(0.007)$ & $0.040^{*}$ & $(0.017)$ \\
\hline Family & $0.168^{* * * *}$ & $(0.026)$ & $0.577^{* * *}$ & $(0.080)$ & $0.167^{* * *}$ & $(0.026)$ & $0.573^{* * *}$ & $(0.081)$ & $0.174^{* * *}$ & $(0.026)$ & $0.577^{* * * *}$ & $(0.081)$ \\
\hline Family: Persons in working age & $0.084^{* * * *}$ & $(0.008)$ & $0.132^{* * *}$ & $(0.030)$ & $0.086^{* * *}$ & $(0.008)$ & $0.134^{* * *}$ & $(0.030)$ & $0.085^{* * *}$ & $(0.008)$ & $0.133^{* * * *}$ & $(0.030)$ \\
\hline Other & $-0.135^{* * *}$ & $(0.040)$ & $0.318^{* * *}$ & $(0.066)$ & $-0.131^{* * *}$ & $(0.040)$ & $0.321^{* * *}$ & $(0.066)$ & $-0.134^{* * *}$ & $(0.039)$ & $0.321^{* * *}$ & $(0.066)$ \\
\hline Other: Persons in working age & $0.168^{* * * *}$ & $(0.017)$ & -0.045 & $(0.031)$ & $0.167^{* * * *}$ & $(0.017)$ & -0.046 & $(0.031)$ & $0.169^{* * * *}$ & $(0.017)$ & -0.047 & $(0.031)$ \\
\hline Quality of public transport & & & & & & & & & & & & \\
\hline Level A: very good & & & (ref.) & & & & (ref.) & & & & (ref.) & \\
\hline Level B: good & & & $0.260^{* * *}$ & $(0.029)$ & & & $0.257^{* * * *}$ & $(0.029)$ & & & $0.253^{* * *}$ & $(0.028)$ \\
\hline Level C: moderate & & & $0.501^{* * *}$ & $(0.031)$ & & & $0.495^{* * * *}$ & $(0.032)$ & & & $0.463^{* * * *}$ & $(0.031)$ \\
\hline Level D: low & & & $0.655^{* * *}$ & $(0.034)$ & & & $0.641^{* * * *}$ & $(0.034)$ & & & $0.599^{* * *}$ & $(0.034)$ \\
\hline Level E: very low & & & $0.838^{* * *}$ & $(0.039)$ & & & $0.828^{* * *}$ & $(0.039)$ & & & $0.787^{* * *}$ & $(0.039)$ \\
\hline Constant & $8.857^{* * *}$ & $(0.042)$ & $-1.346^{* * *}$ & $(0.047)$ & $8.855^{* * *}$ & $(0.040)$ & $-1.331^{* * *}$ & $(0.047)$ & $8.806^{* * *}$ & $(0.040)$ & $-1.250^{* * *}$ & $(0.046)$ \\
\hline $\operatorname{arctanh}(\rho)$ & $-0.114^{* * *}$ & $(0.033)$ & & & $-0.089^{* *}$ & $(0.030)$ & & & $-0.070^{*}$ & $(0.027)$ & & \\
\hline $\log (\sigma)$ & $-0.436^{* * *}$ & $(0.005)$ & & & $-0.438^{* * *}$ & & $(0.005)$ & & $-0.439^{* * *}$ & $(0.005)$ & & \\
\hline Observations & 40932 & & & & 40932 & & & & 40932 & & & \\
\hline Censored observations & 10274 & & & & 10274 & & & & 10274 & & & \\
\hline Log-likelihood & -43363.3 & & & & 43335.0 & & & & 43300.6 & & & \\
\hline
\end{tabular}


Table 5: Results of the Heckman model using unpooled accessibility variables.

\begin{tabular}{|c|c|c|c|c|c|c|c|c|c|c|c|c|}
\hline & \multicolumn{4}{|c|}{ Scenario 1} & \multicolumn{4}{|c|}{ Scenario 2} & \multicolumn{4}{|c|}{ Scenario 3} \\
\hline & \multicolumn{2}{|c|}{ Log of annual mileage } & \multicolumn{2}{|c|}{ Car household } & \multicolumn{2}{|c|}{ Log of annual mileage } & \multicolumn{2}{|c|}{ Car household } & \multicolumn{2}{|c|}{ Log of annual mileage } & \multicolumn{2}{|c|}{ Car household } \\
\hline \multicolumn{13}{|l|}{ Accessibility } \\
\hline H-H-H & (ref.) & & (ref.) & & (ref.) & & (ref.) & & (ref.) & & (ref.) & \\
\hline H-H-M & -0.005 & $(0.022)$ & 0.030 & $(0.040)$ & -0.032 & $(0.018)$ & 0.035 & $(0.031)$ & $-0.041^{*}$ & $(0.019)$ & $-0.081^{* *}$ & $(0.030)$ \\
\hline H-H-L & $-0.080^{* * *}$ & $(0.017)$ & $0.082^{* *}$ & $(0.031)$ & $-0.158^{* * *}$ & $(0.021)$ & $0.072^{*}$ & $(0.036)$ & $0.062^{*}$ & $(0.027)$ & $0.128^{* *}$ & $(0.045)$ \\
\hline H-M-H & & & & & & & & & 0.028 & $(0.031)$ & $0.167^{* *}$ & $(0.063)$ \\
\hline H-M-M/L & & & & & & & & & $0.161^{* * * *}$ & $(0.031)$ & 0.094 & $(0.060)$ \\
\hline $\mathrm{H}-\mathrm{M}-\mathrm{H} / \mathrm{M} / \mathrm{L}$ & 0.015 & $(0.030)$ & 0.036 & $(0.057)$ & 0.036 & $(0.032)$ & $0.140^{*}$ & $(0.068)$ & & & & \\
\hline M-H-H & & & & & & & & & $0.129^{* * * *}$ & $(0.033)$ & 0.071 & $(0.068)$ \\
\hline M-H-M & & & & & & & & & 0.003 & $(0.038)$ & 0.137 & $(0.071)$ \\
\hline M-H-L & & & & & & & & & $0.215^{* * * *}$ & $(0.045)$ & $0.601^{* * * *}$ & (0.098) \\
\hline $\mathrm{M}-\mathrm{H}-\mathrm{H} / \mathrm{M} / \mathrm{L}$ & -0.024 & $(0.029)$ & -0.099 & $(0.059)$ & 0.030 & $(0.032)$ & $0.164^{*}$ & $(0.076)$ & & & & \\
\hline $\mathrm{M}-\mathrm{M}-\mathrm{H} / \mathrm{M} / \mathrm{L}$ & $0.068^{* * * *}$ & $(0.014)$ & $0.187^{* * *}$ & $(0.028)$ & $0.070^{* * *}$ & $(0.015)$ & $0.230^{* * * *}$ & $(0.028)$ & $0.142^{* * * *}$ & $(0.014)$ & $0.226^{* * * *}$ & $(0.028)$ \\
\hline M-L-H/M & $0.098^{* *}$ & $(0.030)$ & $0.279^{* * * *}$ & (0.068) & & & & & & & & \\
\hline M-L-H/M/L & & & & & $0.126^{* * *}$ & $(0.023)$ & $0.232^{* * * *}$ & $(0.053)$ & $0.174^{* * * *}$ & $(0.026)$ & $0.188^{* *}$ & $(0.061)$ \\
\hline L-M-H/M/L & $0.097^{* *}$ & $(0.033)$ & $0.515^{* * *}$ & $(0.072)$ & $0.149^{* * *}$ & $(0.022)$ & $0.357^{* * * *}$ & $(0.047)$ & $0.182^{* * *}$ & $(0.026)$ & $0.355^{* * *}$ & $(0.058)$ \\
\hline L-L-H/M/L & $0.112^{* * *}$ & $(0.016)$ & $0.287^{* * *}$ & $(0.031)$ & $0.125^{* * *}$ & $(0.017)$ & $0.316^{* * * *}$ & $(0.034)$ & $0.220^{* * *}$ & $(0.018)$ & $0.269^{* * *}$ & $(0.038)$ \\
\hline \multicolumn{13}{|l|}{ Gross monthly household income } \\
\hline Less than CHF 2'000 & (ref.) & & (ref.) & & (ref.) & & (ref.) & & (ref.) & & (ref.) & \\
\hline CHF 2'000 to 4'000 & 0.005 & $(0.033)$ & $0.383^{* * *}$ & $(0.040)$ & 0.006 & $(0.033)$ & $0.376^{* * *}$ & $(0.039)$ & 0.009 & $(0.033)$ & $0.376^{* * *}$ & $(0.039)$ \\
\hline CHF $4^{\prime} 001$ to $6^{\prime} 000$ & $0.152^{* * *}$ & $(0.034)$ & $0.953^{* * *}$ & $(0.040)$ & $0.160^{* * *}$ & $(0.033)$ & $0.944^{* * * *}$ & $(0.040)$ & $0.163^{* * * *}$ & $(0.033)$ & $0.939^{* * *}$ & $(0.040)$ \\
\hline CHF 6'001 to 8'000 & $0.258^{* * *}$ & $(0.034)$ & $1.232^{* * * *}$ & $(0.043)$ & $0.267^{* * *}$ & $(0.034)$ & $1.220^{* * * *}$ & $(0.043)$ & $0.271^{* * * *}$ & $(0.034)$ & $1.214^{* * * *}$ & $(0.043)$ \\
\hline CHF 8'001 to $10^{\prime} 000$ & $0.374^{* * *}$ & $(0.035)$ & $1.333^{* * *}$ & $(0.047)$ & $0.383^{* * *}$ & $(0.034)$ & $1.321^{* * *}$ & $(0.047)$ & $0.386^{* * *}$ & $(0.034)$ & $1.312^{* * *}$ & $(0.047)$ \\
\hline CHF $10^{\prime} 001$ to $12^{\prime} 000$ & $0.416^{* * *}$ & $(0.036)$ & $1.498^{* * *}$ & $(0.055)$ & $0.425^{* * *}$ & $(0.036)$ & $1.486^{* * * *}$ & $(0.055)$ & $0.428^{* * *}$ & $(0.035)$ & $1.474^{* * *}$ & $(0.055)$ \\
\hline CHF $12^{\prime} 001$ to $14^{\prime} 000$ & $0.422^{* * *}$ & $(0.039)$ & $1.542^{* * *}$ & $(0.071)$ & $0.433^{* * *}$ & $(0.038)$ & $1.533^{* * *}$ & $(0.071)$ & $0.436^{* * *}$ & $(0.038)$ & $1.520^{* * * *}$ & $(0.071)$ \\
\hline CHF $14^{\prime} 001$ to $16^{\prime} 000$ & $0.503^{* * * *}$ & $(0.040)$ & $1.492^{* * *}$ & $(0.081)$ & $0.515^{* * *}$ & $(0.039)$ & $1.480^{* * * *}$ & $(0.081)$ & $0.521^{* * *}$ & $(0.039)$ & $1.474^{* * * *}$ & $(0.082)$ \\
\hline More than CHF 16'000 & $0.501^{* * * *}$ & $(0.039)$ & $1.671^{* * * *}$ & $(0.074)$ & $0.511^{* * * *}$ & $(0.038)$ & $1.658^{* * * *}$ & $(0.074)$ & $0.515^{* * * *}$ & $(0.038)$ & $1.641^{* * * *}$ & $(0.074)$ \\
\hline \multicolumn{13}{|l|}{ Spatial typology } \\
\hline Centers & (ref.) & & (ref.) & & (ref.) & & (ref.) & & (ref.) & & (ref.) & \\
\hline Suburban & $0.144^{* * *}$ & $(0.012)$ & $0.366^{* * *}$ & $(0.022)$ & $0.133^{* * * *}$ & $(0.011)$ & $0.347^{* * * *}$ & $(0.021)$ & $0.089^{* * * *}$ & $(0.012)$ & $0.272^{* * * *}$ & $(0.022)$ \\
\hline High-income & $0.148^{* * * *}$ & $(0.021)$ & $0.428^{* * * *}$ & $(0.045)$ & $0.126^{* * *}$ & $(0.021)$ & $0.416^{* * * *}$ & $(0.045)$ & $0.079^{* * * *}$ & $(0.021)$ & $0.326^{* * * *}$ & $(0.045)$ \\
\hline Periurban & $0.259^{* * *}$ & $(0.015)$ & $0.534^{* * *}$ & $(0.036)$ & $0.238^{* * *}$ & $(0.014)$ & $0.498^{* * * *}$ & $(0.036)$ & $0.181^{* * * *}$ & $(0.015)$ & $0.432^{* * * *}$ & $(0.037)$ \\
\hline Touristic & $0.109^{* * *}$ & $(0.028)$ & $0.150^{* *}$ & $(0.057)$ & $0.092^{* *}$ & $(0.028)$ & $0.131^{*}$ & $(0.058)$ & 0.037 & $(0.029)$ & 0.109 & $(0.059)$ \\
\hline Industry and tertiary sector & $0.221^{* * * *}$ & $(0.018)$ & $0.321^{* * *}$ & $(0.041)$ & $0.198^{* * * *}$ & $(0.018)$ & $0.292^{* * * *}$ & $(0.042)$ & $0.133^{* * *}$ & $(0.020)$ & $0.264^{* * *}$ & $(0.046)$ \\
\hline Rural-commuting & $0.332^{* * *}$ & $(0.020)$ & $0.508^{* * *}$ & $(0.053)$ & $0.307^{* * *}$ & $(0.020)$ & $0.474^{* * * *}$ & $(0.053)$ & $0.240^{* * * *}$ & $(0.022)$ & $0.426^{* * *}$ & $(0.055)$ \\
\hline Mixed-agrarian & $0.264^{* * *}$ & $(0.021)$ & $0.499^{* * *}$ & $(0.052)$ & $0.241^{* * *}$ & $(0.021)$ & $0.467^{* * *}$ & $(0.053)$ & $0.175^{* * *}$ & $(0.023)$ & $0.440^{* * * *}$ & $(0.055)$ \\
\hline Agrarian & $0.340^{* * *}$ & $(0.046)$ & $0.286^{* *}$ & $(0.104)$ & $0.319^{* * *}$ & $(0.046)$ & $0.262^{*}$ & $(0.105)$ & $0.255^{* * * *}$ & $(0.046)$ & $0.243^{*}$ & $(0.106)$ \\
\hline \multicolumn{13}{|l|}{ Household type } \\
\hline Single & (ref.) & & (ref.) & & (ref.) & & (ref.) & & (ref.) & & (ref.) & \\
\hline Couple & $-0.164^{* * *}$ & $(0.015)$ & $0.675^{* * *}$ & $(0.027)$ & $-0.159^{* * *}$ & $(0.014)$ & $0.673^{* * * *}$ & $(0.027)$ & $-0.158^{* * *}$ & $(0.014)$ & $0.672^{* * *}$ & $(0.027)$ \\
\hline Couple: Persons in working age & $0.237^{* * *}$ & $(0.007)$ & $0.035^{*}$ & $(0.017)$ & $0.237^{* * *}$ & $(0.007)$ & $0.036^{*}$ & $(0.017)$ & $0.237^{* * * *}$ & $(0.007)$ & $0.039^{*}$ & $(0.017)$ \\
\hline Family & $0.165^{* * *}$ & $(0.026)$ & $0.579^{* * *}$ & $(0.080)$ & $0.169^{* * *}$ & $(0.026)$ & $0.573^{* * *}$ & $(0.080)$ & $0.173^{* * *}$ & $(0.026)$ & $0.581^{* * *}$ & $(0.081)$ \\
\hline Family: Persons in working age & $0.085^{* * *}$ & $(0.008)$ & $0.131^{* * *}$ & $(0.030)$ & $0.086^{* * *}$ & $(0.008)$ & $0.134^{* * * *}$ & $(0.030)$ & $0.085^{* * *}$ & $(0.008)$ & $0.132^{* * * *}$ & $(0.030)$ \\
\hline Other & $-0.135^{* * *}$ & $(0.040)$ & $0.319^{* * *}$ & $(0.066)$ & $-0.130^{* * *}$ & $(0.040)$ & $0.323^{* * *}$ & $(0.066)$ & $-0.134^{* * *}$ & $(0.039)$ & $0.322^{\text {**** }}$ & $(0.066)$ \\
\hline Other: Persons in working age & $0.168^{* * * *}$ & $(0.017)$ & -0.045 & $(0.031)$ & $0.167^{* * * *}$ & $(0.017)$ & -0.047 & $(0.031)$ & $0.168^{* * *}$ & $(0.017)$ & -0.047 & $(0.031)$ \\
\hline \multicolumn{13}{|l|}{ Quality of public transport } \\
\hline Level A: very good & & & (ref.) & & & & (ref.) & & & & (ref.) & \\
\hline Level B: good & & & $0.264^{* * *}$ & $(0.028)$ & & & $0.261^{* * *}$ & $(0.028)$ & & & $0.260^{* * * *}$ & $(0.028)$ \\
\hline Level C: moderate & & & $0.503^{* * *}$ & $(0.031)$ & & & $0.487^{* * * *}$ & $(0.031)$ & & & $0.471^{* * * *}$ & $(0.031)$ \\
\hline Level D: low & & & $0.657^{* * *}$ & $(0.034)$ & & & $0.628^{* * *}$ & $(0.034)$ & & & $0.607^{* * * *}$ & $(0.034)$ \\
\hline Level E: very low & & & $0.840^{* * * *}$ & $(0.039)$ & & & $0.816^{* * * *}$ & $(0.039)$ & & & $0.795^{* * * *}$ & $(0.039)$ \\
\hline Constant & $8.862^{* * * *}$ & $(0.042)$ & $-1.344^{* * *}$ & $(0.047)$ & $8.849^{* * *}$ & $(0.040)$ & $-1.324^{* * *}$ & $(0.046)$ & $8.816^{* * *}$ & $(0.040)$ & $-1.239^{* * *}$ & $(0.046)$ \\
\hline $\operatorname{arctanh}(\rho)$ & $-0.122^{\text {**** }}$ & $(0.034)$ & & & $-0.085^{* *}$ & $(0.030)$ & & & $-0.080^{* *}$ & $(0.028)$ & & \\
\hline $\log (\sigma)$ & $-0.435^{* * *}$ & $(0.005)$ & & & $-0.437^{* * *}$ & & $(0.005)$ & & $-0.438^{* * *}$ & $(0.005)$ & & \\
\hline Observations & 40932 & & & & 40932 & & & & 40932 & & & \\
\hline Censored observations & 10274 & & & & 10274 & & & & 10274 & & & \\
\hline Log-likelihood at convergence & -43387.2 & & & & -43360.3 & & & & 43321.7 & & & \\
\hline
\end{tabular}


After pooling levels for the accessibility variable, we have 9 levels left in scenario 1 and 2, while for scenario 3 we recovered 11 levels. We find that still not all levels are significant. In the remainder of this paper, we focus on the effects of the pooled model with threshold values from the third scenario, because the third scenario scores best in terms of the Akaike Information Criterion (AIC) and provides most significant accessibility estimates.

To gain a better understanding of the estimates of the new accessibility measure, we illustrate them as a grouped bar chart in Figure 4 and, second, their spatial distribution across Switzerland on a map in Figure 5. From the bar chart, we derive three findings. First, we observe again less driving in dense developments as the coefficients generally decline from low to high population levels. Second, when considering all estimates for population levels Low, Medium and High separately, we observe the trend of a reduction in driving when the number of workplaces increases or when the competition for workplaces is reduced. Third, regarding the control for accessibility to workplaces in $R 2$, we do not find significant differences in the workplace distribution for all levels. However, in two cases we find significant differences: between $M-H-L$ and $M-H-H$ as well as $H-H-L$ and $H-H-H$ we observe that more accessible jobs reduce driving. We find the estimate of $H-H-M$ significant and negative. We consulted the list of TAZs at this level and found that $40 \%$ of observation in the $H-H-M$ level are located within Berne, Lausanne and Zurich. The others are located in the suburbs close to the cities. Therefore, we attribute this estimate to the issue of arbitrarily setting the travel time threshold (Morris et al., 1979; Geurs and van Wee, 2004).

We also show the spatial distribution of the estimates across Switzerland in Figure 5. To better understand the spatial distribution in context of workplace distribution, we add the boundaries of the labor market regions, as indicated in thick black lines, and the labor market centers, indicated by red dots, to the figure using data from Killer and Axhausen (2010). Generally, we find that the estimates increase with distance to the labor market center and thus, are largest at the borders of the labor market. Thus, our model estimates replicate the labor market regions and centers defined by Killer and Axhausen (2010). In Figure 6 we show the spatial distribution of average effects from the new accessibility measure, the quality of public transport and the spatial typology. We obtained the values by predicting for each zone the average mileage, holding all non-spatial covariates at their mean. For the reader's convenience, we subtract from the predictions their minimum value. Thus, the legend key indicates the expected additional annual mileage compared to Zurich, which exhibited in this case the lowest expected average annual mileage. This spatial illustration also shows the previous finding of increased driving with greater distance to the labor market center. Concluding, these findings support our hypothesis that the need for driving increases in areas with less jobs available compared to the population.

Lastly, the estimates of the control variables for households' annual mileage show the expected 
effect of income, household type and macroscopic spatial typology. We found in both equations the effects of the control variables robust against the three scenarios, because effects of the control variables in both equations change only in the second or third significant figure. 
Figure 4: Illustration of pooled model estimates.

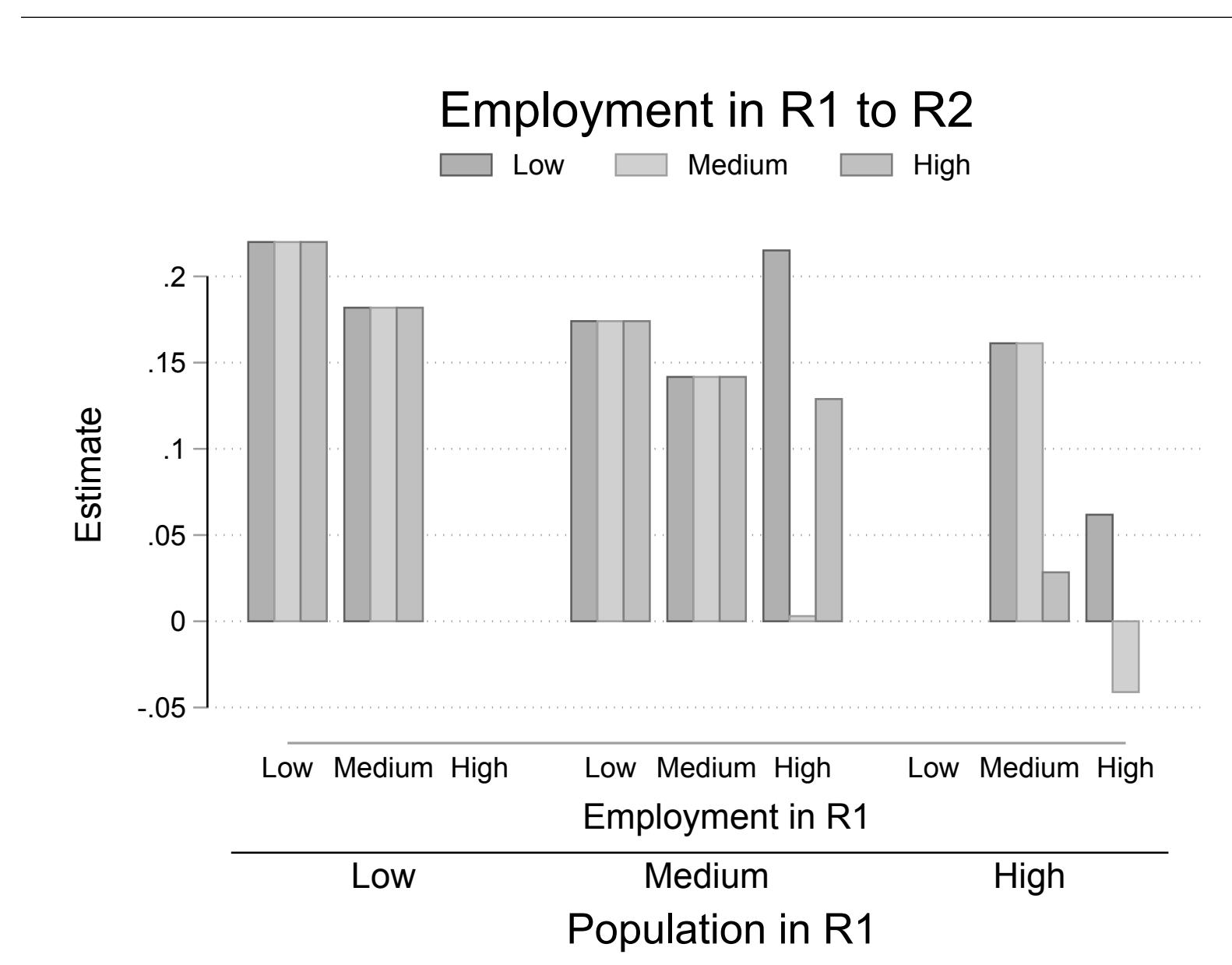

Note: Estimates from the third scenario. 
Figure 5: Spatial distribution of accessibility estimates from the pooled model, third scenario. The boundaries and marked centroids refer to the Swiss labor market regions as determined by Killer and Axhausen (2010).

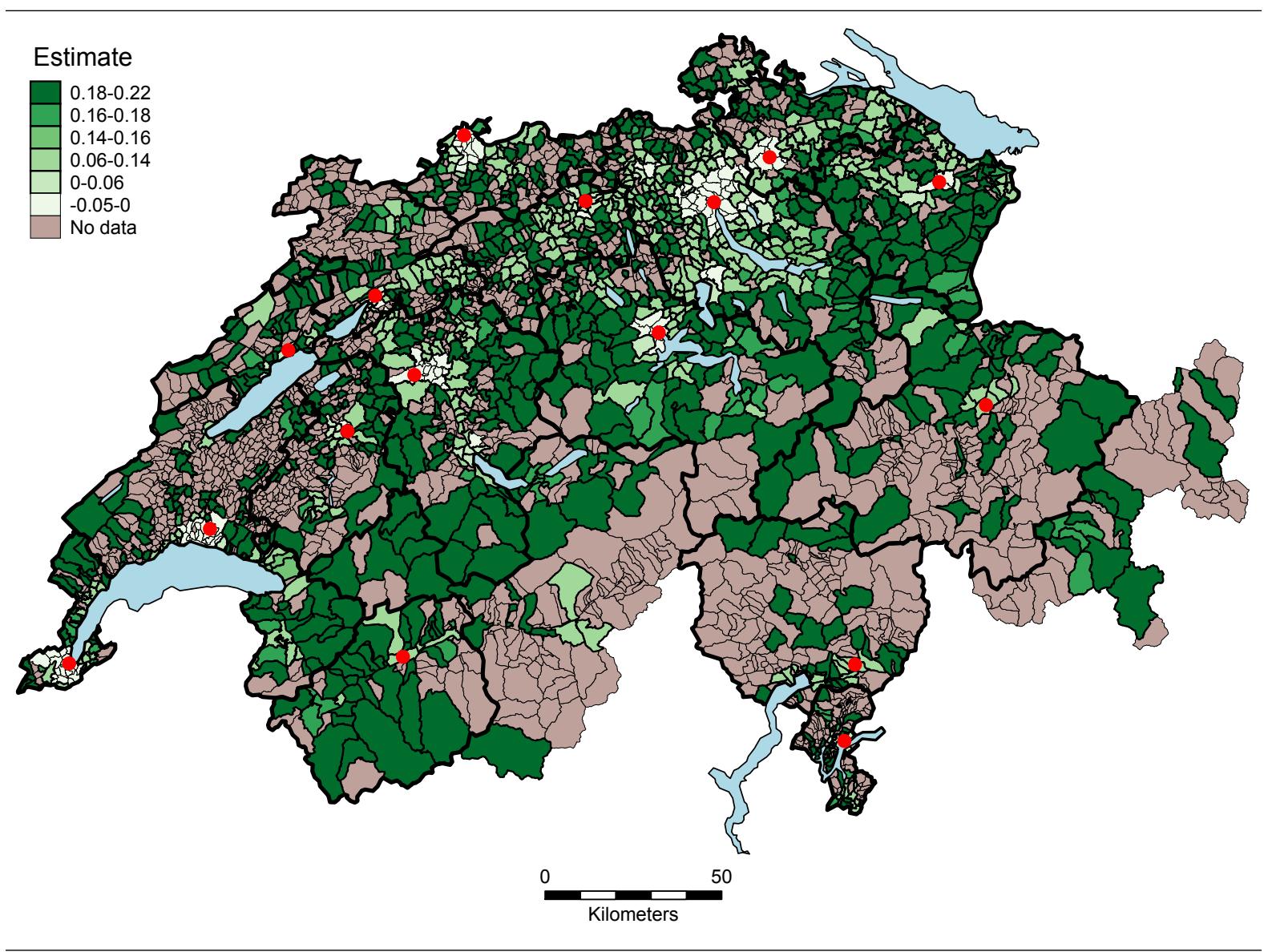


Figure 6: Expected average additional annual mileage for each zone compared to Zurich. The boundaries and marked centroids refer to the Swiss labor market regions as determined by Killer and Axhausen (2010).

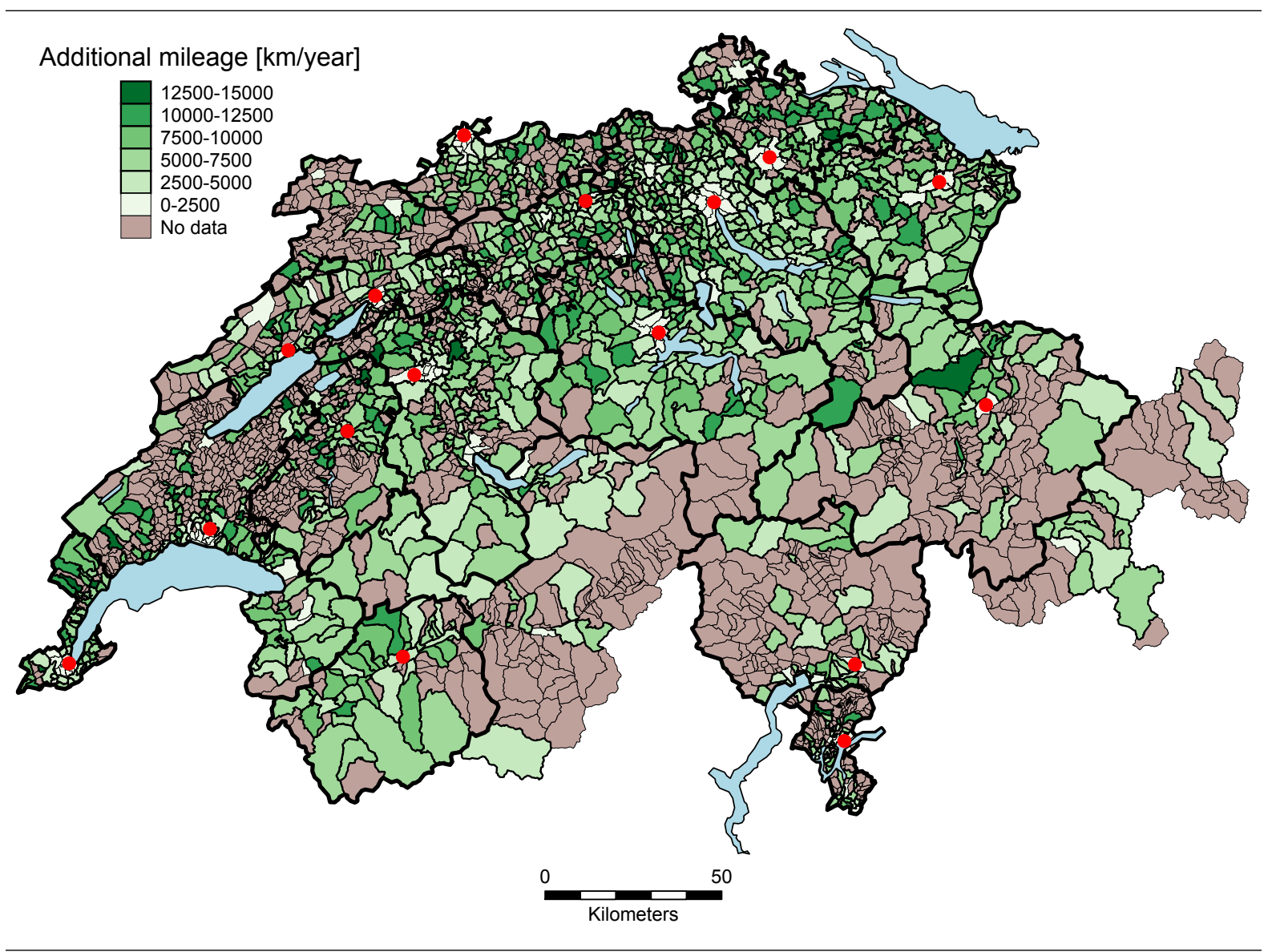




\section{Discussion}

The results presented align within the existing literature: dense developments reduce driving (Ewing and Cervero, 2010), income affects car ownership and use positively (Dargay et al., 2007 ) and the effects of accessibility change with the shape and extent of zones (Ma and Banister, 2006). The results also support our hypothesis that less competition for available workplaces reduces driving. Nonetheless, as no one best measure of accessibility exists (Handy and Niemeier, 1997) our proposed measure and methodology faces limitations and requires discussion.

The objective of our study was to analyze the effects of competition for opportunities with special focus on the labor market. We decided to measure competition as local population competing for local workplaces, but we measure driving as the annual mileage that covers all trip purposes by all household members. Thus, the model estimates do not precisely reflect commuting behavior. We believe that this measure is appropriate to discuss the relationships between the distribution of population, workplaces and driving, because one third of trips are work related and this is the only coherent measure offered by the census as households did not report on commuting mode. However, we have to acknowledge a chance of an omitted variable bias, although we control with well understood variables. For example, Cervero and Duncan (2006) compared the metrics of jobs-housing balance and retail-housing mix with respect to their effect on driving and they found significant differences. So far, this analysis has not addressed the use of public transport, although in Switzerland quality public transport offers many households to be carless, because our motivation was to quantify the effects on driving due to its negative externalities. However, for developing optimal land-use strategies, future research must analyze the effects of competition for workplaces on the use of public transport as well, but, as the microcensus does not report the annual public transport mileage, this analysis might be more difficult.

Similar to all other cumulative opportunity measures, the proposed new accessibility measure faces the issue of arbitrary chosen threshold values (Morris et al., 1979; Vickerman, 1974). This could lead to the problem that some destinations with a large amount of opportunities are located at the margin of the area considered, as we expect happened in case of our negative estimate for $H-H-M$. Regarding this measure, Geurs and van Wee (2004) concluded that "the measures are not very useful as input in social and economic evaluations of land-use and transport changes", but the scope of the proposed accessibility measure is not one of the mentioned objectives.

The computation of the three cumulative opportunities measures of accessibility and then our new accessibility variable relied on macroscopic travel times from TAZ to TAZ. Although this is common practice in literature, e.g. Owen and Levinson (2015), the analysis would benefit from 
including access and egress times, especially in light of rather large TAZs. This would add an individual component to the new accessibility measure (Geurs and van Wee, 2004). Each of the three continuous cumulative opportunities measures of accessibility is transformed to a three level ordinal variable, but there are no restrictions for future research to increase the number of levels to achieve a more detailed resolution. Lastly, we also see no restrictions to apply the suggested approach to gravity-based accessibility measures, introduced by Hansen (1959).

From a methodological perspective, we demonstrated the explanatory power of the new accessibility measure for modeling households' annual mileage with a Heckman correction for carless households. However, the proposed accessibility measure is not restricted to this application. The accessibility measure could also be applied to more advanced econometric models of car ownership and use, for example, Bento et al. (2005) and Bhat and Sen (2006). Future research could also use the concept of the new accessibility measure to explain individual disaggregated travel behavior, by using trip specific opportunities instead of a single kind of opportunities.

In the literature section, we mentioned excess commuting as another approach to discuss the relationship between the distribution of population, workplaces and driving. The model estimates here do not answer the question on how much driving is in excess or wasteful, because we do not consider individuals' residential and workplace location choices. However, our accessibility measure reflects the constraints resulting from the distribution of population and workplaces, similar to excess commuting, but our measure is operationalized as a land-use measure and, thus, is capable of describing a spatial distribution. Arguably, our estimates quantify the need for commuting, although obtained from all trip purposes in the annual mileage. Figures 5 and 6 illustrate this as locations at the borders of labor market regions exhibit the largest annual mileage. Lastly, we have to note that the proposed accessibility measure is also a measure of the jobs-housing balance, but due to its operationalization as a measure of the built environment, it will never become a key indicator for excess commuting, see Kanaroglou et al. (2015).

So far, this study has not addressed the issue of residential self-selection (Mokhtarian and Cao, 2008). In reviewing empirical literature, Cao et al. (2009) reported for most studies decreased effects of the built environment on driving when controlled for residential self-selection, while Ewing and Cervero (2010) found no such or increased effects. Ewing and Cervero argued that the differences could result either from the way they operationalized self-selection or the different samples they used. As this effect is still unclear and the number of studies controlling for residential self-selection is rather small, future research should - whenever possible - contribute to this field. 


\section{Conclusion}

In this paper, we proposed a new measure of accessibility for analyzing travel behavior. Typically, relatively easy to understand measures of accessibility fail to consider the competition for opportunities, e.g. limited local availability of jobs for a local population (Geurs and van Wee, 2004). However, our new approach addresses this gap. We used the relatively easy to understand cumulative opportunities measure of accessibility, transformed the measures to ordinal variables and, finally, created the new variable by interacting the ordinal measures of population and workplace accessibility. We applied this new measure to explain differences in households' annual mileage with a Heckman selection method to correct for carless households. We found that differences in annual mileage are not only explained by the general spatial typology, e.g. urban centers, agglomeration and countryside, but also by the compactness of the development and the competition for workplaces - as measured by our new accessibility measure. This is not only in line with general understanding of the relationship between the built environment and travel behavior (Ewing and Cervero, 2010, 2017), but also supports our hypothesis that greater numbers of locally available workplaces or less need to compete for local workplaces reduce driving.

For Swiss transport and land-use planners, our results emphasize that - after controlling for land-use factors such as access to public transport and spatial typology - competition for jobs in a municipality is a factor affecting driving significantly. As Figure 5 and 6 show, annual mileage increases towards the boundaries of the labor market. The main implication from Figure 6 is that the location choice of new residential developments can have a remarkable impact on the nation's total driving and the negative externalities.

Lastly, we do not recommend an optimal land-use strategy that aims to reduce or minimize car driving by sorting all individuals to closer workplaces (or vice versa residence locations), or equally distributing jobs to reduce the need for competing for available workplaces, because people have preferences in their choices and pooling of labor results in productivity gains (Rosenthal and Strange, 2004).

\section{Acknowledgment}

The authors thank the two anonymous referees for their comments on an earlier version of this manuscript. Their thoughts contributed a lot to the outcome of this paper. The authors also would like to thank Basil Schmid for his comments. This work was supported by ETH Research 
Grant ETH-04 15-1. 


\section{References}

Barr, S., A. Fraszczyk and C. Mulley (2010) Excess travelling-what does it mean? new definition and a case study of excess commuters in Tyne and Wear, UK, European Transport Research Review, 2, 69-83.

Bento, A. M., M. L. Cropper, A. M. Mobarak and K. Vinha (2005) The effects of urban spatial structure on travel demand in the United States, Review of Economics and Statistics, 87 (3) 466-478.

Bhat, C. R., S. Astroza, R. Sidharthan, M. J. B. Alam and W. H. Khushefati (2014) A joint countcontinuous model of travel behavior with selection based on a multinomial probit residential density choice model, Transportation Research Part B: Methodological, 68, 31-51.

Bhat, C. R., A. R. Pinjari, S. K. Dubey and A. S. Hamdi (2016) On accommodating spatial interactions in a generalized heterogeneous data model (GHDM) of mixed types of dependent variables, Transportation Research Part B: Methodological, 94, 240-263.

Bhat, C. R. and S. Sen (2006) Household vehicle type holdings and usage: an application of the multiple discrete-continuous extreme value (MDCEV) model, Transportation Research Part B: Methodological, 40, 35-53.

Cao, X. J., P. L. Mokhtarian and S. L. Handy (2009) Examining the impacts of residential self selection on travel behaviour: A focus on empirical findings, Transport Reviews, 29, 359-395.

Cervero, R. and M. Duncan (2006) Which reduces vehicle travel more: Jobs-housing balance or retail-housing mixing?, Journal of the American Planning Association, 72 (4) 475-490.

Cervero, R. and K. Kockelman (1997) Travel demand and the 3Ds: Density, diversity, and design, Transportation Research Part D-Transport and Environment, 2 (3) 199-219.

Clark, S. D. (2007) Estimating local car ownership models, Journal of Transport Geography, 15 (3) 184-197.

Crozet, Y., A. Mercier and N. Ovtracht (2012) Accessibility: a key indicator to assess the past and future of urban mobility, in Accessibility analysis and Transport Planning Challenges for Europe and North America, 263-279.

Dargay, J., D. Gately and M. Sommer (2007) Vehicle ownership and income growth, worldwide: 1960-2030, The Energy Journal, 28, 143-170.

Ewing, R. and R. Cervero (2010) Travel and the built environment, Journal of the American Planning Association, 76, 265-294. 
Ewing, R. and R. Cervero (2017) "Does compact development make people drive less?" The answer is yes, Journal of the American Planning Association, 83 (1) 19-25.

Geurs, K. T. and B. van Wee (2004) Accessibility evaluation of land-use and transport strategies: review and research directions, Journal of Transport Geography, 12 (2) 127-140.

Hamilton, A., Bruce W.; Röell (1982) Wasteful commuting, Journal of Political Economy, 90 (5) 1035-1053.

Hamilton, B. W. (1989) Wasteful commuting again, Journal of Political Economy, 97 (6) 1497-1504.

Handy, S. L. and D. A. Niemeier (1997) Measuring accessibility: An exploration of issues and alternatives, Environment and Planning A, 29 (7) 1175-1194.

Hansen, W. G. (1959) How accessibility shapes land use, Journal of the American Institute of Planners, 25 (2) 73-76.

Heckman, J. J. (1976) The common structure of statistical models of truncation, sample selection and limited dependent variables and a simple estimator for such models, Annals of Economic and Social Measurement, 5, 475-492.

Heckman, J. J. (1979) Sample selection bias as a specification error, Econometrica, 47, 153-161.

Horner, M. W. (2004) Spatial dimensions of urban commuting: A review of major issues and their implications for future geographic research, The Professional Geographer, 56 (2) $160-173$.

Kanaroglou, P. S., C. D. Higgins and T. a. Chowdhury (2015) Excess commuting: A critical review and comparative analysis of concepts, indices, and policy implications, Journal of Transport Geography, 44, 13-23.

Karlaftis, M. and J. Golias (2002) Automobile ownership, households without automobiles, and urban traffic parameters: Are they related?, Transportation Research Record, 1792, 29-35.

Killer, V. and K. W. Axhausen (2010) Mapping overlapping commuting-to-work areas, Journal of Maps, 6 (1) 147-159.

Killer, V., R. Fuhrer, D. Guth, C. Holz-Rau and K. W. Axhausen (2013) Road accessibility of Germany and Switzerland 1970-2007, Arbeitsberichte Verkehrs- und Raumplanung, 936.

Ma, D., Kang-Rae; Banister (2006) Extended excess commuting: A measure of the jobs-housing imbalance in seoul, Urban Studies, 43 (11) 2099-2113. 
Ma, K. and D. Banister (2006) Excess commuting: A critical review, Transport Reviews, 26, 749-767.

Mokhtarian, P. L. and X. Cao (2008) Examining the impacts of residential self-selection on travel behavior: A focus on methodologies, Transportation Research Part B: Methodological, 42, 204-228.

Morris, J. M., P. L. Dumble and M. R. Wigan (1979) Accessibility indicators for transport planning, Transportation Research Part a-Policy and Practice, 13 (2) 91-109.

Owen, A. and D. M. Levinson (2015) Modeling the commute mode share of transit using continuous accessibility to jobs, Transportation Research Part A: Policy and Practice, 74, 110-122.

Rosenthal, S. S. and W. C. Strange (2004) Evidence on the nature and sources of agglomeration economies, in J.-F. Henderson, J.Vernon; Thisse (ed.) Handbook of Regional and Urban Economics, vol. 4, 2119-2171.

Swiss Federal Office of Spatial Development (ARE) (2011) ÖV-Güteklassen - Berechnungsmethodik ARE, Neuchâtel.

Swiss Federal Office of Spatial Development (ARE), Swiss Federal Office of Environment (BAFU) and Swiss Federal Statistical Office (BFS) (2011) Landschaftstypologie Schweiz.

Swiss Federal Office of Statistics (BFS) and Swiss Federal Office of Spatial Development (ARE) (2012) Mobilität in der Schweiz - Ergebnisse des Mikrozensus Mobilität und Verkehr 2010, Neuchâtel.

Vickerman, R. W. (1974) Accessibility, attraction, and potential: A review of some concepts and their use in determining mobility, Environment and Planning A, 6 (6) 675-691.

Weis, C. and K. W. Axhausen (2009) Induced travel demand: Evidence from a pseudo panel data based structural equations model, Research in Transportation Economics, 25 (1) 8-18. 